\title{
Empirical Study on the Effect of Organizational Culture on Organization Innovation
}

\author{
Kambiz Abdi ${ }^{1} \&$ Aslan Amat Senin ${ }^{1}$ \\ ${ }^{1}$ Department of Business Administration, Faculty of Management, Universiti Teknologi Malaysia, Johor, \\ Malaysia \\ Correspondence: Aslan Amat Senin, Department of Business Administration, Faculty of Management, Universiti \\ Teknologi Malaysia, 81310 skudai, Johor, Malaysia. E-mail: aslan@utm.my
}

Received: August 12, 2015 Accepted: September 19, 2015 Online Published: September 23, 2015

doi:10.5539/ass.v11n23p114 URL: http://dx.doi.org/10.5539/ass.v11n23p114

\begin{abstract}
The character of organizational innovation is considered significant for improving the products, procedures and bazaars for increasing the value as well as effectiveness of administrations. The innovation procedure is important to the performance of association as the capability for the innovation is important for obtaining and supporting competitive benefit. Few empirical investigations were conducted regarding the consequence of organizational culture on organizational innovation by Organizational Learning particularly over the developing countries. The most important objective of the current investigating is to evaluate the consequence of organizational culture on innovation directly and over Organizational Learning in Iranian automotive industry i.e. Iran Khodro Company. A total of 272 managers were nominated from systems and methods as the participants of the current the current investigation. The data were examined applying the Structural Equation Modelling (SEM). The results of the current investigation revealed that Organizational Learning has an important character as a mediator on the association between organizational culture and organizational innovation. In the current study, the one research model is suggested.
\end{abstract}

Keywords: organizational culture, organizational innovation, organizational learning

\section{Introduction}

Innovation refers to the economic development which could be considered as a source of sustained competitive advantage of the companies. Based on the managers' viewpoint, the main goal of innovation is to present change in the association for making new chances or achievement of the current ones. Additionally, innovation reforms the modest landscape and makes novel bazaar occasions. The innovation is considered important for the activities of organization as the capability to invent is important to obtain and sustain competitive advantage (McEvily \& Chakravarthy, 2002). Current study focuses on the character of organizational category over that of innovation category for improving our information regarding the innovation in administrations. As the organization is considered as the initial setting for innovation, innovation cannot be investigated separately regarding the kind of organization which makes or adopts it (Damanpour et al., 2009). Consequently, innovation is identified in several manners. Though, it is identified as making the new information and concepts to improve novel business results for developing the internal business procedures and assemblies and to make market driven goods and service.

Although this concept seems to be very important, few studies have been conducted on the organization cultural (OC) barriers that might influence the association between organizational learning (OL) and organizational innovation (OI) results, and few studies were done on how cultural barriers affects the disposition of a company's current knowledge base and thus improves innovation. Considering the association between OL and innovation, it seems that innovation is significant as a basis of competitive advantage. Several investigations in this regard concluded that culture is an important issue for the OL procedure. Therefore, OC might improve learning or be a main barrier as it relies on the values it inspires (Liao \& Wu, 2010).

According to the related literature, few studies were conducted in the automobile industry, in that there are merely a few investigations focused on the association between OC and OL (Azadi et al., 2013; Czerniewicz \& Brown, 2009). Additionally, learning and OC are typically depends on societal and cultural circumstances. Furthermore, few investigations simultaneously inspect the consequence of several kinds of OC i.e. clan 
adhocracy, hierarchy and market culture on OI through showing the mediating consequence of OL. Also, Liao and $\mathrm{Wu}$ (2010) proposed some variables which has been taken into account simultaneously and few comprehensive investigations evaluated that. Therefore, learning the connections between those variables in Iran Khodro could be considered as the contribution of fostering the innovation in that setting. Sanz-Valle et al., (2011) revealed that the association between OL and OI and recognizing that innovation is significant and is considered as the basis of competitive advantage. Therefore, for fostering OL and, consequently, innovation, businesses should try to make their managers ready for improving the OC, which fosters both, OL and OI. Current investigation tried to examine the following research questions:

1) Does the OC affect OI?

2) Is there any association between OC and OL?

3) Is OL holding any connectivity with OI?

4) Does the OL mediate the relationship between OC and OI?

\section{Contribution of the Research}

$\mathrm{OC}$ as well as $\mathrm{OL}$ are considered as the key issues for developing an innovative work setting and association (Azadi et al., 2013; Czerniewicz \& Brown, 2009). Consequently, to deliver a better definition about the association between OC and perceptions toward OI, current investigation attempted to evaluate the effect of several kinds of OC on OL. Additionally, the outcomes of the current study can aid us to obtain a truthful vision regarding the $\mathrm{OC}$ on the $\mathrm{OL}$ and $\mathrm{OI}$, based on the introduction of the study and research purposes

\subsection{Organization Culture}

OC is considered as a significant topic in university as well as commercial circumstances (Alvesson, 2012). The competing values outline was planned by Quinn and Rorbaugh (1983), to evaluate the culture of an association. It is recognized as one of the most significant business models through the $20^{\text {th }}$ century. There is an agreement on the notion that administrations usually try to present a culture that inspires communication over their members and inspires workers to obtain an innovation and positive working situation. Current study uses a quantitative approach in the sociological-functionalist tradition through considering that organizations have cultures. Organizations with this culture apply observation and resistance to obtain advanced level of efficiency and competitiveness. Based on Cameron and Quinn (2006), OC is considered as the set of important standards, perceptions, and standards shared by supporters of an association. OC has two critically significant tasks to incorporate members, so that they distinguish how to tell to one another and to help the association for adopting the external circumstance. Investigations in this regard show that congruence between individual and OC helps to better steps of performance. Consequently, without a consistent change in OC, helps to shift an administration's consequences have a low chance of obtaining "enduring improvement in organizational performance"

\subsection{Organization Learning}

The knowledge range i.e. OL refers to the organizational theory to understand theories and models about the way an association adapts and studies (Vasenska, 2013). OL is considered as one of the key equipment to obtain continuing achievement of an association (Argote, 2013; Easterby-Smith \& Lyles, 2011; Liao \& Wu, 2010). To improve its ability to learn, an association must create a system, in that individual learning might be shared amongst members as learning by a person shapes the foundation of OL; it is usually considered as individual teaching that an organization also learn as a whole. In organizational improvement, learning refers to the feature of an adaptive association, i.e., an association that is able to sense variations in signals from its setting (both internal and external) and adapt consequently (Smith et al., 2005). Based on Senge (1994),a learning organization is a place in that people frequently improve their aptitude to make the consequences they truthfully wish, where new and extensive patterns of thinking are nurtured, where collective aspiration is set free, and where people are frequently learning how to learn with each other.

\subsection{Organization Innovation}

There is great arrangement that innovation is an essential capability for the future of any company and maybe an important issue of long term existence. Innovation might be considered as a swirl of novel ideas, novel procedure, and novel goods. It is clear that we need to know how each of these sides crops, procedures and thoughts interplay to retain businesses competitive in the future through improving economic value and the development of necessary in the market (Cooke, 2001; Marins, 2008). Innovation then is considered as an ongoing procedure of learning, searching and exploring that results in novel foodstuffs, novel methods, novel forms of 
administrations and finally new marketplaces. Sustaining innovation is one of the most vexing difficulties faced in commercial (Amabile et al., 1996). Innovation is considered as one of those business issues which includes a huge field of investigating and still the usable consequences that a director might apply as a roadmap to obtain sustained innovation are deeply missing. Certainly, a critical issue in innovation, that of sense-making of novel thoughts, might be considered as the most critical reference issue for the people attracted in sustaining novelty. Innovation then is considered as an continuing procedure of acquiring, probing and investigating that ends in novel crops, novel methods, novel methods of administrations and finally novel marketplaces. There is a rising accord that OL is a an important strategic variable and one that drives novelty. OI is defined as the ideas' application that are supposed as new to an association, whether the novelty is signified in organisation, procedures, marketing systems, or crops (Weerawardena et al., 2006). It seems that the learning of organization is highly associated to OI. It is important to identify the kinds of innovation along with their features for the reason that a sure type of innovation wants unique and sophisticated replies from an association (Hurmelinna-Laukkanen et al., 2008).

In the current study, the knowledge-based theory is considered as an appropriate theory for supporting the conceptual framework. The knowledge based view (KBV) of an association focuses on the character of knowledge to identify and influence the performance. Current investigation improves empirical KBV investigation that inspects the performance suggestions of substitute organizational modes and offer support regarding the significance of organizational association in organization's knowledge improvement and incorporation events (Macher, 2014). Based on this theory, if OC considered as an immaterial advantage that is done efficiently in several levels of the association leads to some unique abilities and volumes that in turn lead to greater performance over innovation (Leal-Rodríguez et al., 2013).

\subsection{Research Model}

This study attempts is to inspect the effect of OC over OI directly and over mediating variable OL. In the current investigation, a research model was shown and empirically examined. The KBV of company are examined as the chief theoretical framework for predicting and to interpreting the association between variables. Figures 1, 2 and 3 exemplify a model which contains three constructs, like, OC, OL, and OI.

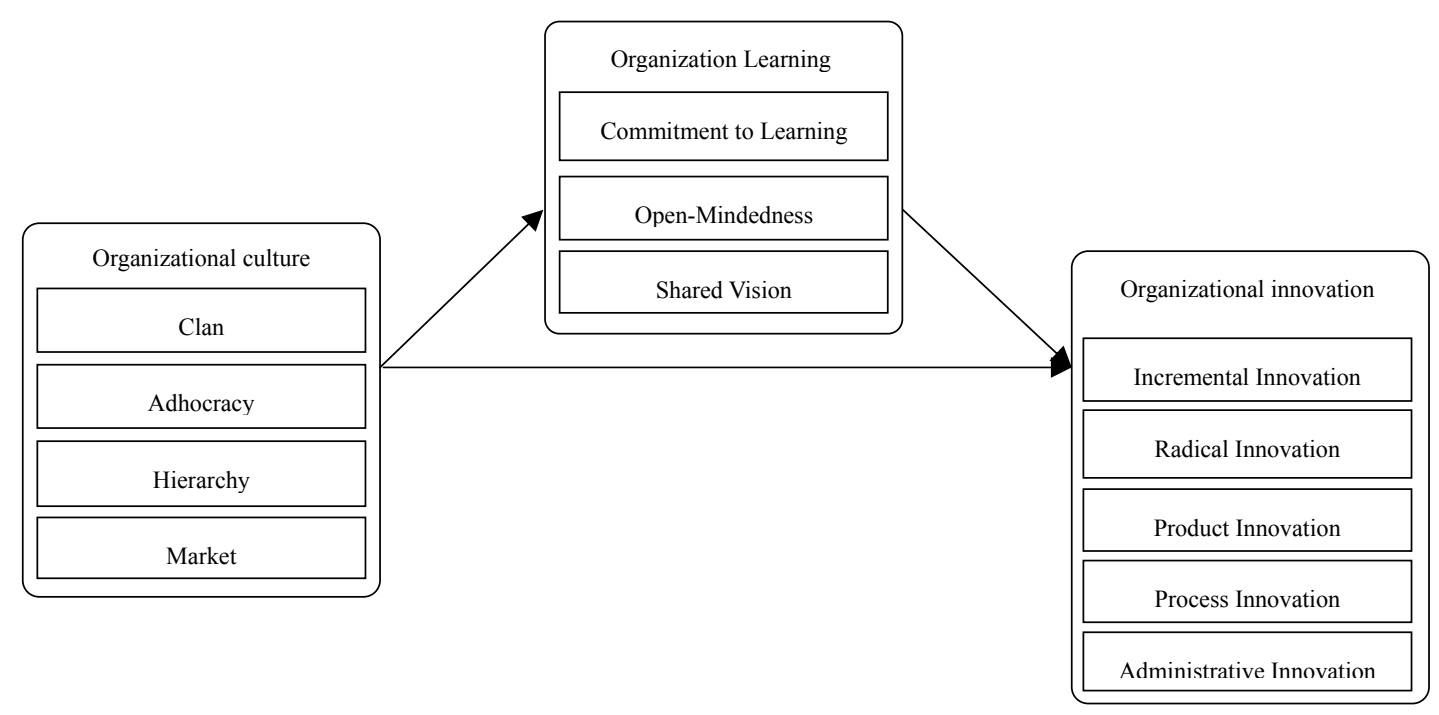

Figure 1. Conceptual framework 


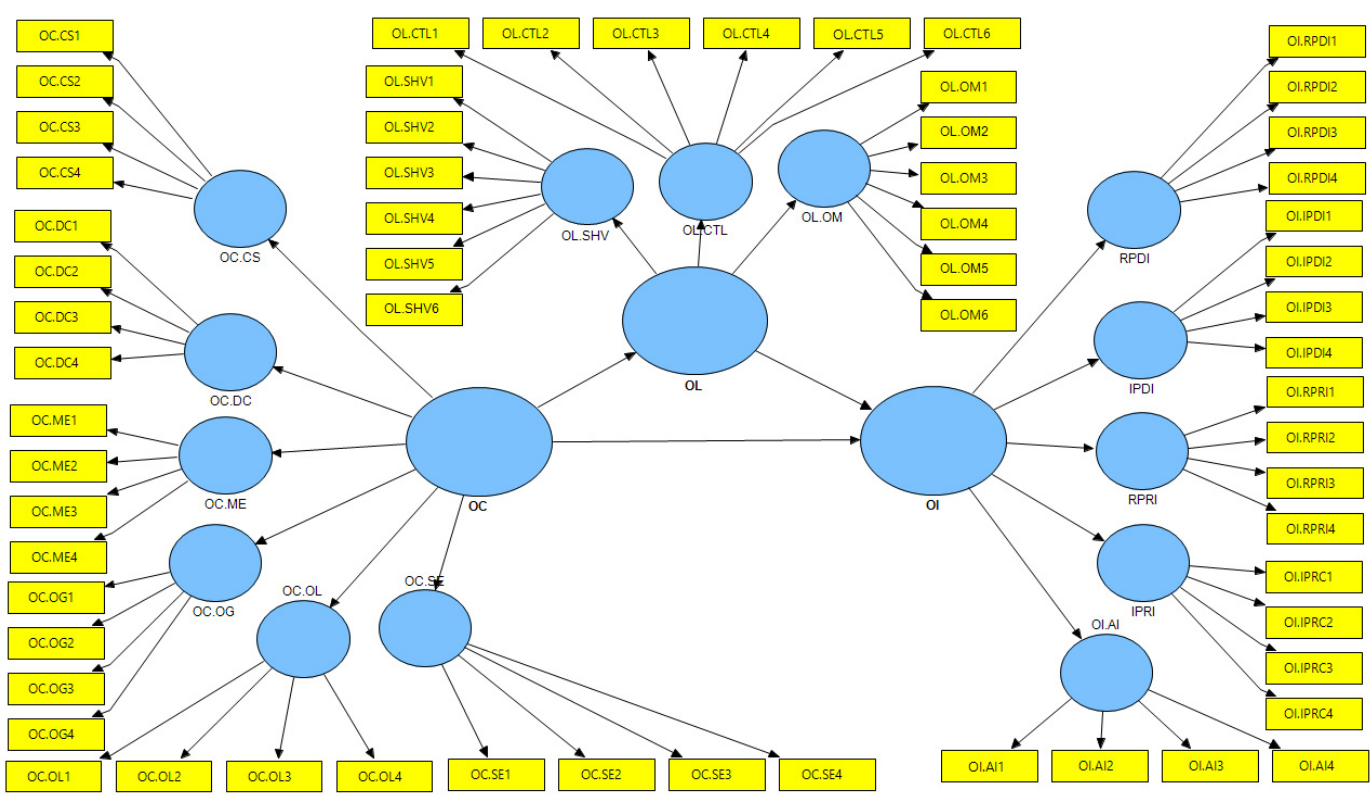

Figure 2. Detailed research model

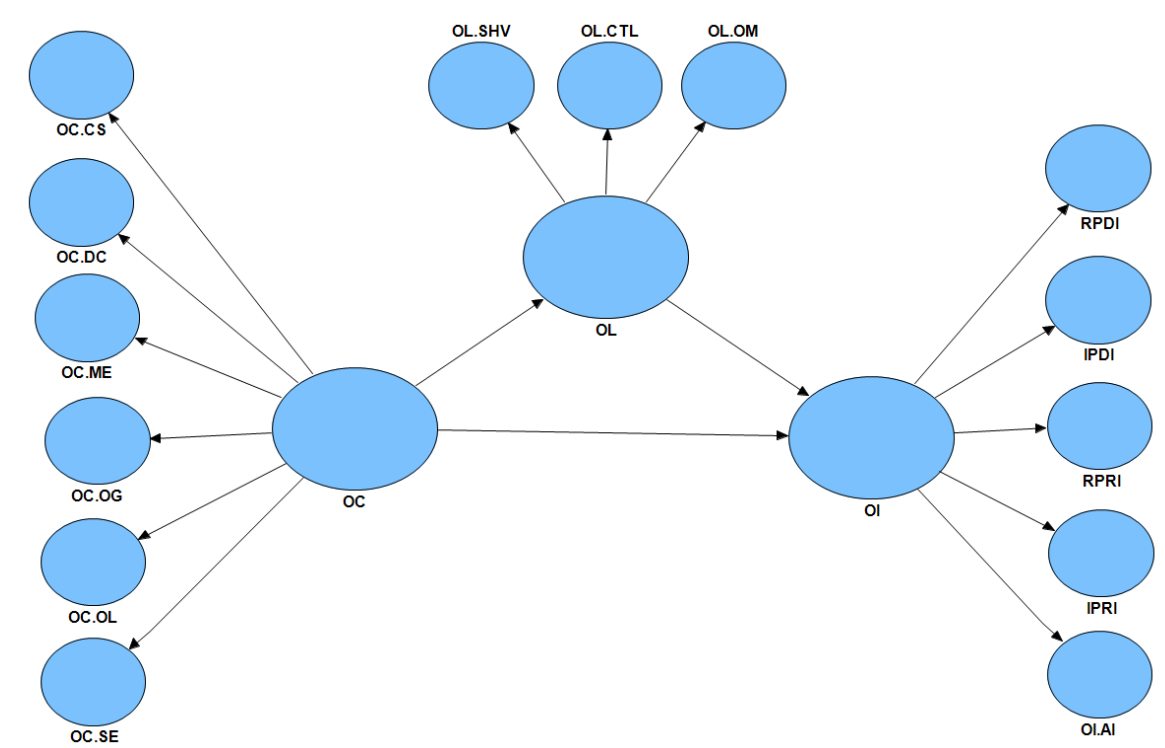

Figure 3. Detailed research model

According to the proposed conceptual framework, following four hypotheses have been employed.

$\mathrm{H}_{1}$ : OC has a positive effect on OI.

$\mathrm{H}_{2}$ : OC has a positive effect on OL.

$\mathrm{H}_{3}$ : OL has a positive effect on OI.

$\mathrm{H}_{4}$ : OL mediates the relationship between $\mathrm{OC}$ on OI.

\section{Methods}

The hypotheses of this paper have been developed with the help of supporting theory. This study chooses survey with questionnaire that allows hypothesis testing and generalizing findings. On the basis of previous empirical studies and literature review, questionnaire has been developed. Therefore, a questionnaire based survey was conducted to furnish ample evidence for potential moderating factors. This study can be classified as a cross-sectional study, since it measures the relationship between OL, OC and OI within a particular time period. 


\subsection{Sample}

The target populations selected for this research is auto parts manufacturing of one of the largest car manufacturer company in Iran namely IKCO. According to the statistics of the company, 850 employees in the company that are classified in three groups namely, metallic, electrical and polymer are based on the requirements of automotive industry. As a result, the sampling frame for the current study includes a variety auto parts manufacturer. The systems and methods managers are surveyed as respondents. The minimum sample size using probability random sampling method is estimated to be 272 shown in Table 1.. Sample size was designed to be adequate to fulfil the Smart PLS analysis requirements. The stratified random sampling method was used for gathering quantitative data, because the stratifying criterion help researcher to be ensure that the resulting sample was distributed in the same way as the population (Bryman \& Bell, 2007).

Table 1. Distribution of the sample size based on the size and type of industry

\begin{tabular}{llllll}
\hline Sub-Sector & Frequency & $\begin{array}{l}\text { Distribution of Sample frame based on the industry type and firm } \\
\text { size } \\
\text { Small }\end{array}$ & Medium & Large & $\begin{array}{l}\text { Sampling } \\
\text { size }\end{array}$ \\
\hline Electric & 81 & 33 & 28 & 20 & 81 \\
Metallic & 114 & 45 & 41 & 28 & 114 \\
Polymer & 77 & 28 & 24 & 24 & 77 \\
Total & 272 & 108 & 92 & 72 & 272 \\
\hline
\end{tabular}

\subsection{Survey Procedure}

An empirical study that is quantitative in nature was conducted in three different groups of Iranian auto parts manufacturers. In the present study, the survey questionnaire method for data collection is selected, which is defined as a predefined set of written closed structure or open-ended items filled by the respondents (Imran et al., 2011). The choice of data collection method in survey research is important because of the time, cost and quality of the collected data. A survey questionnaire is developed in this study following the steps of content and operational-items relevancy to the objective of the research, along with proper wording and layout management (Imran et al., 2011). Data were collected and analysed in two waves. The first was a pilot study performed to analyse the reliability and validity of newly developed measures. Factor analysis and Cronbach's a results indicated acceptable validity and reliability of all study measures. Thus, the pilot study data were combined with the second wave of data, which was collected approximately 2 months after the pilot study data.

\subsection{Measures}

Except for demographic variables, Perceptual measures with a seven point Likert scale are used to measure response. All study items were assessed using 7-point Likert scales (e.g., strongly disagree 1, strongly agree 7).

\subsubsection{Measures-OC}

Four distinct dimensions of OC were examined. These dimensions are: clan culture, adhocracy culture Hierarchy and market culture. However, in order to measure these four distinct dimensions, 6 constructs are conceptualized according to instrument (OCAI) developed by Cameron and Quinn (1999). These dimensions include: Dominant Characteristics, organizational leadership, management of employees, organizational glue, strategic emphases, and criteria for success. The scale includes a list of 24 items (4 questions for each of 6 dimensions). The measures are adopted and validated based on culture assessment instrument (OCAI) developed by Cameron and Quinn (1999).

\subsubsection{Measures-OI}

The innovation process is essential to the performance of organization (Marins, 2008). In this study, Five distinct dimensions of OI were examined that namely radical product innovation, incremental product innovation, radical process innovation, incremental process innovation and administrative innovation (Cheng \& Shiu, 2008). The scale includes a list of 20 items (4 questions for each of 5 dimensions).

\subsubsection{Measures-OL}

Organizational learning is defined as the development of new knowledge or awareness that has potential to affect firm behaviour. Three dimensions of OL were examined. These dimensions are commitment to learning, shared 
vision and open-mindedness (Tobin, 1993). The scale includes a list of 18 questions for assessing OL construct and (6 questions for each of 3 dimensions).

\subsection{Limitations of the Methods}

Some important methodological limitations should be noted. For example, this study is cross-sectional in design, and therefore inferences of causality should be interpreted with caution. Future research might examine these relationships by employing experimental or longitudinal designs. In addition, the use of single-source data raises questions regarding common method bias. However, we employed multiple procedural remedies suggested by (Podsakoff \& Organ, 1986) to limit this bias, including ensuring respondents' anonymity, randomizing the order of presentation of survey items as well as conducting a Harman's (1976) single-factor test to assess if any issue regarding common method bias exist.

Common method bias or common method variance refers to the circumstances where a single factor account for a majority of the variance, and a general factor would be apparent (Podsakoff \& Organ, 1986). Common method variance may be of problem and this problem has its roots in the self-reported nature of the data. To remedy a problem of common method bias/variance, data needs to be tested using a Harman's (1976) single-factor test (Podsakoff \& Organ, 1986). Harman's single-factor test involves analysing all variables in an exploratory factor analysis and examining the unrotated factor solution. Data were applied to IBM SPSS factor analysis procedure and this time only a single factor was extracted. The results shows that 19 Eigenvalues are above 1.0 and using principal axis factoring without rotation, the single forced factor accounts for only $24.24 \%$ of the overall variance. Since the percentage is below $50 \%$, therefore, an existence of no general factor is evident and hence common method bias/variance is not an issue for further analysis in this study.

\section{Results}

This study used a variance-based partial least squares (PLS) approach or so called partial least squares structural equation modelling (PLS-SEM) that is a second generation multivariate technique (Fornell \& Cha, 1994). A software called Smart PLS M3 version 2.0 (Ringle et al., 2005) has been used for data analysis purposes. The reason to use PLS-SEM is based on the main aim of this study as to identify and investigate a model in which OI is explained by OC and learning. In circumstances where the focus is on overall prediction of a model, a prediction-oriented or variance-based PLS-SEM approach is particularly suitable (Henseler et al., 2012; Henseler et al., 2009). Furthermore, due to complexity of the model which could cause series of problem for covariance-based techniques, PLS-SEM approach has been employed in this study. In fact, PLS algorithm is established on a series of ordinary least squares regressions (OLS) whereby PLS-SEM as a robust technique can easily handle complex models and non-normally distributed data (Klarner et al., 2013). The analysis should be carried out on the basis of the path weighting scheme (Henseler et al., 2012; Henseler et al., 2009). This study uses recent guidelines provided by Chin (2010), Gil-Garcia (2008), and others (Hair et al., 2013; Hair et al., 2011; Hairet al., 2012, 2013; Hair et al., 2012; Hair et al., 2012).

PLS-SEM as a second generation multivariate technique (Fornell \& Cha, 1994) is capable of carrying out a simultaneous evaluation of the measurement model (the relationships between constructs and their corresponding indicators), and the structural model with the aim of minimizing the error variance (Chin, 1998a; Gil-Garcia, 2008). As recommended by given authors, a measurement model analysis should be carried out prior to evaluation of a structural model. At this stage, the goodness of measures was established through convergence validity, discriminant validity, and composite reliability. Finally, a bootstrapping methods with 3,000 re-samples should be run to determine the significance levels for loadings, weights, and path coefficients (Chin, 1998b; Gil-Garcia, 2008).

\subsection{Measurement Model}

Convergent validity: Convergent validity is the degree to which multiple items to measure the same concept are in agreement. As suggested by Hair et al. effect (2013) factor loadings, composite reliability and average variance extracted have been used to assess convergence validity. The recommended values for loadings are set at $>0.5$, the average variance extracted (AVE) should be $>0.5$ and the composite reliability (CR) should be $>$ 0.7. From Figure 3 it can be seen that all three constructs in the model are conceptualized as second order constructs. Thus this study followed the method suggested in the literature in PLS which is the repeated indicator approach to model the second order factors in the PLS analysis (Hair et al., 2013). From Table 2 Measurement Model, it can be seen that the results of the measurement model exceeded the recommended values thus indicating sufficient convergence validity. Hence, all items for given constructs have been remained in the model for further analysis except for Commitment to learning, Open Mindedness, Shared Vision. One item from each 
commitment to learning and Shared Vision have been removed while two items was removed from open mindedness because of loading less than 0.7 .

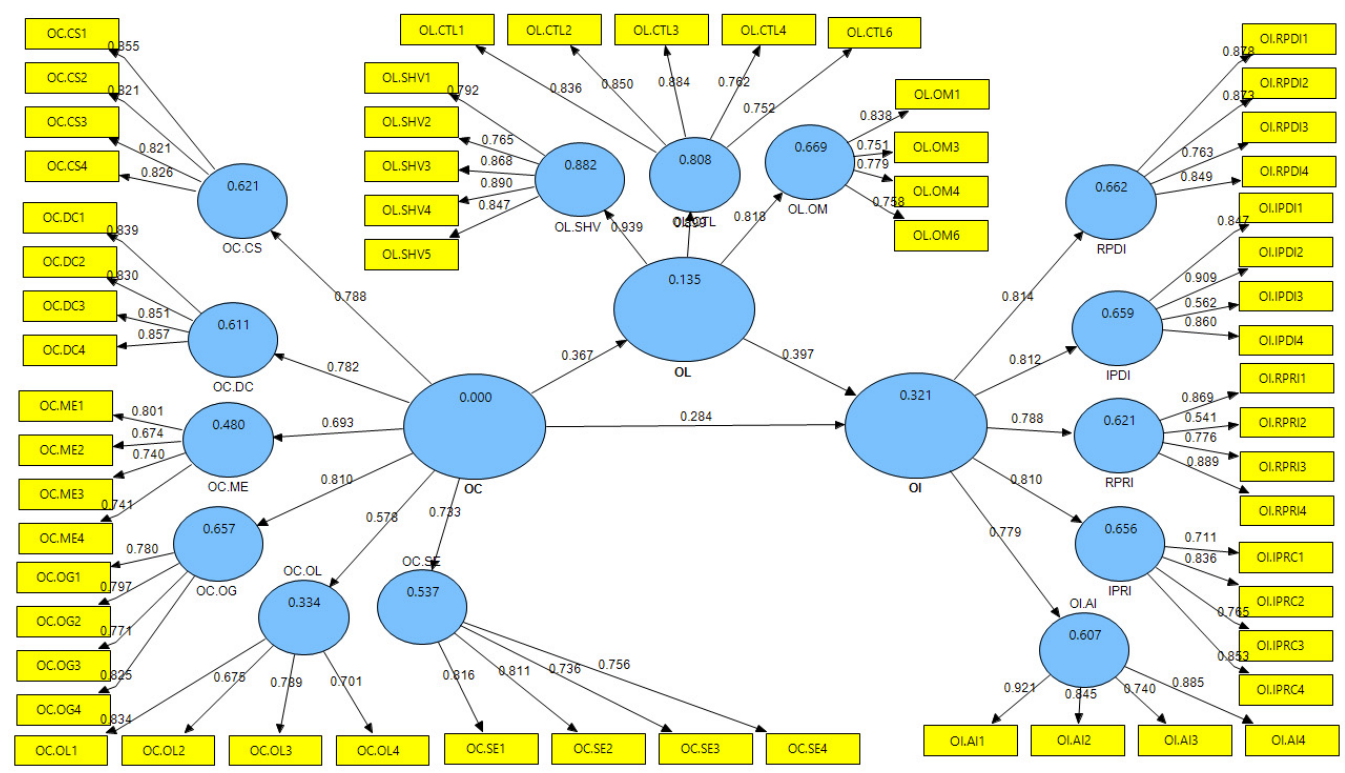

Figure 4. The result of measurement model

Table 2. Measurement model

\begin{tabular}{|c|c|c|c|c|c|}
\hline First-Order Constructs & $\begin{array}{l}\text { Second Order } \\
\text { constructs }\end{array}$ & Items & Loadings & $\mathbf{A V E} \mathbf{E}^{\mathbf{a}}$ & $\mathbf{C R}^{\mathbf{b}}$ \\
\hline \multirow{4}{*}{ OC: Criteria for Success } & & OC.CS1 & 0.855 & 0.690 & 0.899 \\
\hline & & OC.CS2 & 0.821 & & \\
\hline & & OC.CS3 & 0.821 & & \\
\hline & & OC.CS4 & 0.826 & & \\
\hline \multirow{4}{*}{ OC: Dominant Characteristics } & & OC.DC1 & 0.839 & 0.713 & 0.908 \\
\hline & & OC.DC2 & 0.830 & & \\
\hline & & OC.DC3 & 0.851 & & \\
\hline & & OC.DC4 & 0.857 & & \\
\hline \multirow{4}{*}{ OC: Management of Employees } & & OC.ME1 & 0.801 & 0.548 & 0.829 \\
\hline & & OC.ME2 & 0.674 & & \\
\hline & & OC.ME3 & 0.741 & & \\
\hline & & OC.ME4 & 0.740 & & \\
\hline \multirow{4}{*}{ OC: Organization Glue } & & OC.OG1 & 0.780 & 0.630 & 0.872 \\
\hline & & OC.OG2 & 0.797 & & \\
\hline & & OC.OG3 & 0.771 & & \\
\hline & & OC.OG4 & 0.825 & & \\
\hline \multirow{4}{*}{ OC: Organizational Leadership } & & OC.OL1 & 0.834 & 0.566 & 0.838 \\
\hline & & OC.OL2 & 0.674 & & \\
\hline & & OC.OL3 & 0.789 & & \\
\hline & & OC.OL4 & 0.701 & & \\
\hline \multirow{4}{*}{ OC: Strategic Emphases } & & OC.SE1 & 0.816 & 0.609 & 0.862 \\
\hline & & OC.SE2 & 0.811 & & \\
\hline & & OC.SE3 & 0.736 & & \\
\hline & & OC.SE4 & 0.756 & & \\
\hline $\mathrm{OC}^{\mathrm{c}}$ & & Criteria for Success & 0.788 & 0.54 & 0.874 \\
\hline
\end{tabular}




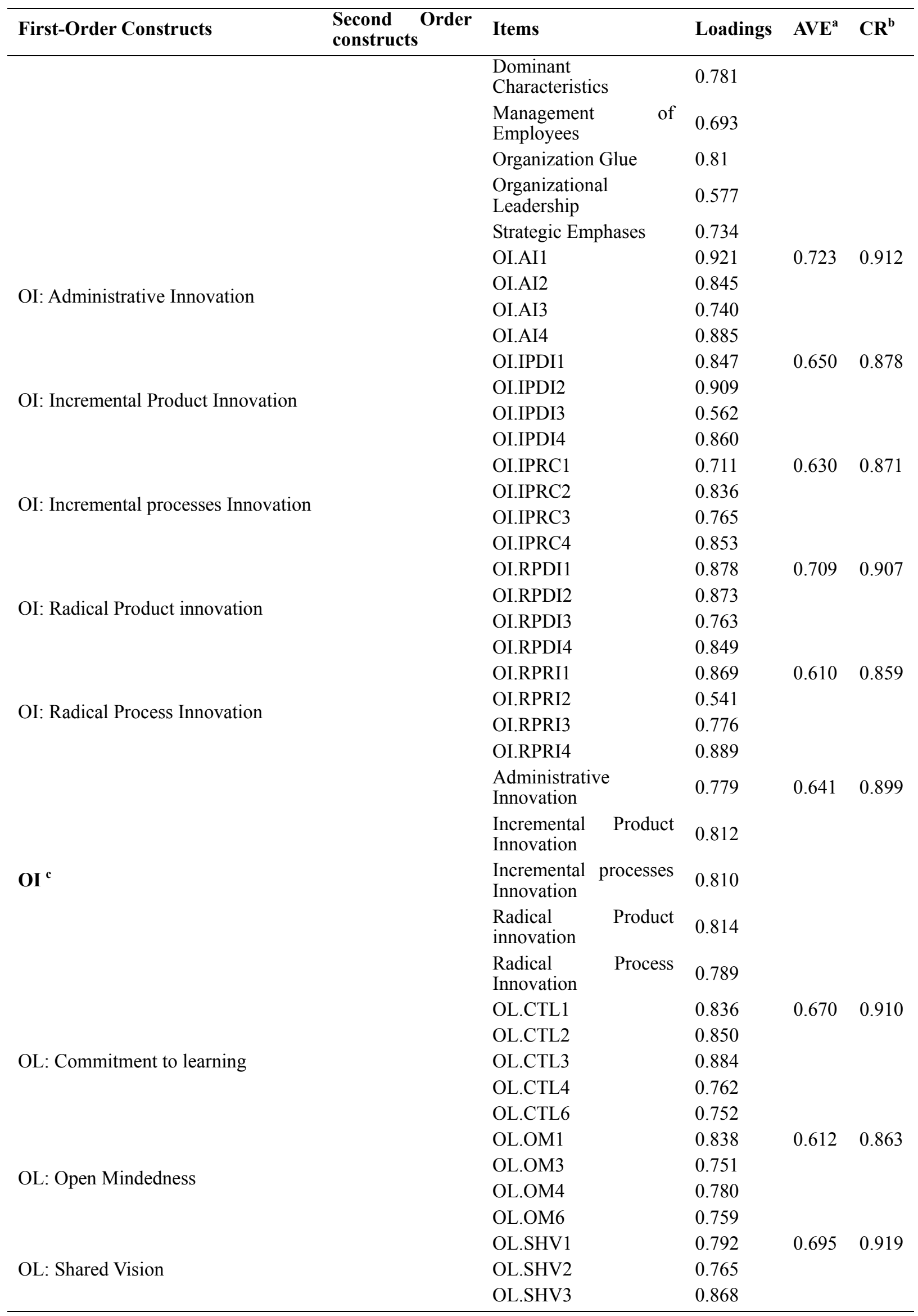




\begin{tabular}{|c|c|c|c|c|c|c|}
\hline First-Order Constructs & $\begin{array}{l}\text { Second Order } \\
\text { constructs }\end{array}$ & Items & & Loadings & $\mathbf{A V E}^{\mathrm{a}}$ & $\mathbf{C R}^{\mathrm{b}}$ \\
\hline \multirow{5}{*}{$O L^{c}$} & & OL.SHV4 & & 0.890 & \multirow{5}{*}{0.787} & \multirow{5}{*}{0.917} \\
\hline & & OL.SHV5 & & 0.847 & & \\
\hline & & $\begin{array}{l}\text { Commitment } \\
\text { learning }\end{array}$ & to & 0.899 & & \\
\hline & & Open Mindedness & & 0.819 & & \\
\hline & & Shared Vision & & 0.939 & & \\
\hline
\end{tabular}

Discriminant validity: Discriminant validity has been assessed using the Fornell and Larcker (1981) method. Discriminant validity is the degree to which items differentiate among constructs or measure distinct concepts (Fornell \& Larcker, 1981). The criterion used to assess this is by comparing the AVE with the squared correlations or the square root of the AVE with correlations. The criterion used to assess this is by comparing the AVE with the squared correlations or the square root of the AVE with correlations. As shown in Table 2, the study uses second method which is to compare the square root of the AVE with the correlations. The criteria is that if the square root of the AVE, shown in the diagonals are greater than the values in the row and columns on that particular construct than we can conclude that the measures discriminant. Table 1.3 shows that the values in the diagonals are greater than the values in their respective row and column thus indicating the measures used in this study are distinct. Thus, the results presented in Tables 3 demonstrate an adequate discriminant and convergent validity.

Table 3. Discriminant validity

\begin{tabular}{llll}
\hline Constructs & 1 & 2 & 3 \\
\hline 1. OC & $\mathbf{0 . 7 3 5}$ & & \\
2. OI & 0.430 & $\mathbf{0 . 8 0 1}$ & $\mathbf{0 . 8 8 7}$ \\
3. OL & 0.367 & 0.501 &
\end{tabular}

*Note. Diagonals represent the square root of the AVE while the off-diagonals represent the correlations.

*The criteria are that the correlation for each variable should be less than square root of AVE presented on diagonals.

\subsection{Structural Model}

To evaluate the structural models' predictive power, $R$ squares $\left(R^{2}\right)$ were calculated. $R$ squares $\left(R^{2}\right)$ indicates the amount of variance explained by the exogenous variables (Barclay et al., 1995). All two variables together explained $32.1 \%$ of the variance in OI. Using a bootstrapping technique with a re-sampling of 3000 , the path estimates and t-statistics were calculated for the hypothesized relationships. Figure 4 shows the structural model analysis. From the analysis it was found $\mathrm{OC}(\beta=0.367, \mathrm{p}<0.01)$ has a positive significant effect on $\mathrm{OL}$ while OC $(\beta=0.284, p<0.01)$ has a positive significant effect on OI. OL $(\beta=0.397, p<0.01)$ has a positive significant effect on OI as shown in Table 4. Thus, all the hypotheses are supported. The result of mediation analysis is reported in the next section.

Table 4. Hypothesis testing-direct relationships

\begin{tabular}{llllll}
\hline Hypothesis & Relationship & Beta & Std Error & t-Value & Supported \\
\hline H1 & OC $\rightarrow$ OI & $0.284^{* * *}$ & 0.060 & 4.717 & Yes \\
H2 & OC $\rightarrow$ OL & $0.367^{* * *}$ & 0.060 & 6.136 & Yes \\
H3 & OL $\rightarrow$ OI & $0.397^{* * *}$ & 0.054 & 7.349 & Yes \\
& & OI & & OL & \\
\multicolumn{2}{l}{ R $^{2}$ Squares for endogenous variables } & $0.32132 .1 \%$ & & 0.135 or $13.5 \%$ \\
\hline
\end{tabular}

$\mathrm{OC}=$ organizational culture; $\mathrm{OI}=$ organizational innovation; \& $\mathrm{OL}=$ organizational learning.

Note: For a 1-tailed hypothesis: ${ }^{*} \mathrm{p}<0.1(\mathrm{t}>1.28),{ }^{* *} \mathrm{p}<0.05(\mathrm{t}>1.645)$, and ${ }^{* * *} \mathrm{p}<0.01(\mathrm{t}>2.33)$, while

For a 2-tailed hypothesis: ${ }^{*} \mathrm{p}<0.1(\mathrm{t}>1.645),{ }^{* *} \mathrm{p}<0.05(\mathrm{t}>1.96)$, and ${ }^{* * *} \mathrm{p}<0.01(\mathrm{t}>2.58)$. 


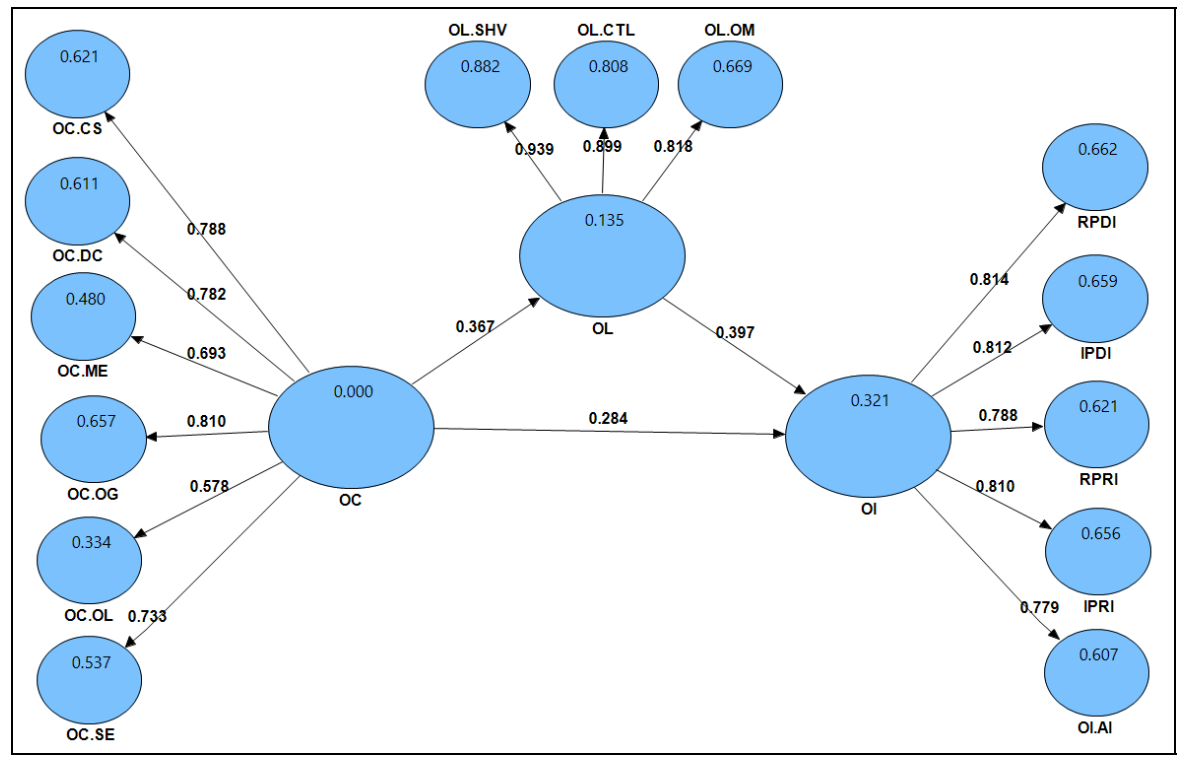

Figure 5. The result of structural model

\subsection{Mediation Analysis}

In order to carry out the mediation analysis, this study adopted the perspective Bollen (1989) articulated and therefore, any evidence of a simple association between $\mathrm{X}$ and $\mathrm{Y}$ is not a precondition of a mediation analysis (as it had been considered as a precondition of mediation analysis by Baron and Kenny (1986)). Therefore, this study follows the most contemporary approach of mediation analysis that is based on Bollen (1989). In given mediation system as a causal system, one causal antecedent $X(\mathrm{OC})$ is proposed as influencing the outcome variable $\mathrm{Y}(\mathrm{OI})$ through one intervening variable $\mathrm{M}(\mathrm{OL})$. The total effect of $\mathrm{X}$ on $\mathrm{Y}$ is partitioned into direct and indirect components. Path from X (OC) to $\mathrm{Y}(\mathrm{OI})$ without passing from $\mathrm{M}(\mathrm{OL})$ is called direct effect and is symbolized as $\left(\mathrm{c}^{\prime}\right)$. The other paths from $\mathrm{X}(\mathrm{OC})$ to $\mathrm{Y}(\mathrm{OI})$ which pass through are $\mathrm{M}(\mathrm{OL})$ is called indirect effects. Indirect effect of $\mathrm{X}$ on $\mathrm{Y}$ through $\mathrm{M}$ only is symbolized as $\mathrm{ab}$. The indirect effect represents how $\mathrm{X}$ (OC) through a causal sequence influence $\mathrm{Y}(\mathrm{OI})$ where $\mathrm{X}(\mathrm{OC})$ influence $\mathrm{M}(\mathrm{OL})$, which in turn $\mathrm{M}(\mathrm{OL})$ influence $\mathrm{Y}$ (OI). The indirect effect passes from antecedent $X(\mathrm{OC})$ to consequent $\mathrm{M}(\mathrm{OL})$ and then from antecedent $\mathrm{M}(\mathrm{OL})$ to consequent $\mathrm{Y}(\mathrm{OI})$ whose coefficient has been symbolized as $\mathrm{a}^{*} \mathrm{~b}$ and calculated as a product of $\mathrm{a}^{*} \mathrm{~b}$.

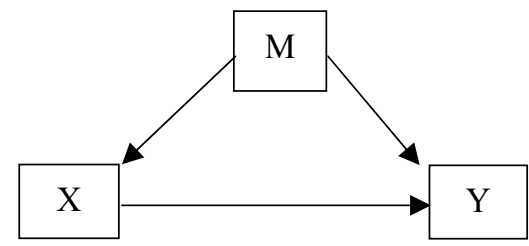

Figure 6. Conceptual diagram-the simple mediation model

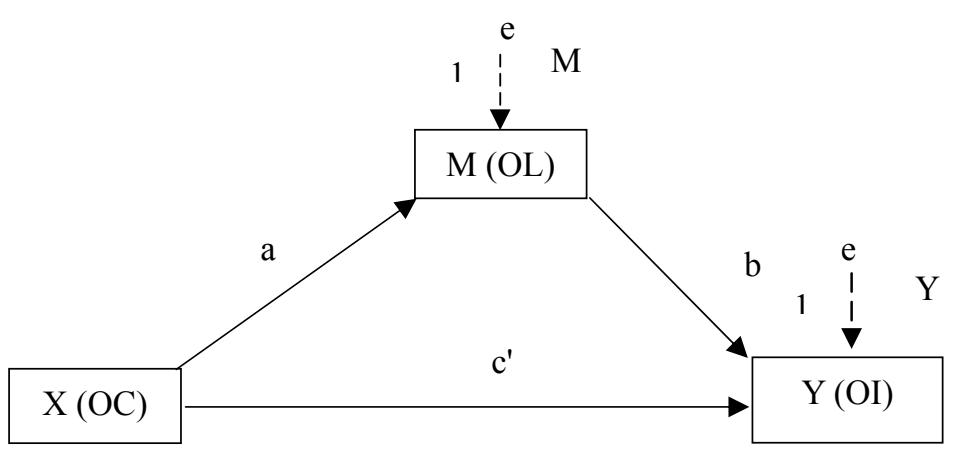

Figure 7. Statistical diagram the simple mediation model

Indirect effect of $\mathrm{X}$ on $\mathrm{Y}$ through $\mathrm{M}=\mathrm{a}$ *b; Direct effect of $\mathrm{X}$ on $\mathrm{Y}=\mathrm{c}^{\prime}$; In this case: $\mathrm{X}=\mathrm{OC}, \mathrm{Y}=\mathrm{OI}$, and $\mathrm{M}=\mathrm{OL}$. 
The first step was to use the latent variable scores (unstandardized) subsequent to measurement model analysis to calculate total, direct and indirect effects, as well as the $95 \%$ confidence interval (CI) for the mediator variables as shown in Table 5 and Table 6 . Next, a bootstrapping procedure (re-sample $\mathrm{N}=10,000$ ) has been run to assess if product of coefficients, which represents the indirect effect, is significant (Hayes, 2013). This step was carried out to obtain bootstrap confidence intervals: bias-corrected (BC). As the result, if the computed interval for a mediating effect does not contain zero, this means that the indirect effect is significantly different from zero with a $95 \%$ confidence level. In this procedure, a t-value or $Z$ scores are calculated as: $Z=a b /(\operatorname{Se}(a b))$.

The results of bootstrapping procedure are presented in following tables. Results suggest that indirect effect is significant. The results demonstrates that the direct of OC on OI or $c^{\prime}$ path is significant $(B=0.299, \alpha=0.000<p$ $=0.01$ ). The effect of all other coefficient paths in the model is significant. Besides, as suggested by Taylor, MacKinnon and Tein, (2008), the ratio of indirect $\left(\mathrm{I}=\mathrm{a}^{*} \mathrm{~b}\right)$ to direct effect $\left(\mathrm{c}^{\prime}\right)$, and indirect effect $\left(\mathrm{I}=\mathrm{a}^{*} \mathrm{~b}\right)$ to total effect $\left(c=c^{\prime}+a^{*} b\right)$ can be calculated as I/D and I/D+I respectively. As suggested by Hair et al. (2013), another criterion to reject or accept a mediating hypotheses depends on the size of the ratio of the indirect effect to the total effect: $\mathrm{I} / \mathrm{D}+\mathrm{I}$, or $\left(\mathrm{a}^{*} \mathrm{~b}\right) /\left(\mathrm{c}=\mathrm{c}^{\prime}+\mathrm{a}^{*} \mathrm{~b}\right)$. This measure is called Variance accounted for $\left(\mathrm{VAF}=\mathrm{ab} /\left(\mathrm{c}^{\prime}+\mathrm{a}^{*} \mathrm{~b}\right)\right)$ and determines the size of indirect effect in relation to total effect (Hair et al., 2013). For OL as the mediator, the ratio of indirect to direct effect $(0.1521 / 0.299)$ equals to $50.8 \%$ and the proportion of indirect effect to the total effect is $(0.1521 /(0.1521+0.299)=33.7 \%)$ as shown Table 7 . Hence, given the VAF measure, it has been supported that: OL mediates the relationship between OC on OI as shown Table 8 . To support the findings, a normal theory test or Sobel (1982) z-test for indirect effects has been carried out using bootstrapping technique to avoid violation of distribution assumption. A bootstrapping technique reduced the risk of facing the indirect effects which are usually positively skewed and kurtosis. The results of normal theory tests or Sobel (1982) z-test is almost identical to procedure where the mediating effect for OL is evident. A normal theory test has also yielded the same coefficients for OL.

Table 5. Direct and total effects $(\mathrm{N}=279)$

\begin{tabular}{|c|c|c|c|c|c|}
\hline Relationships & Coefficient (Unstandardized) & Stnd. Error (SE) & $\mathrm{t}$ & $\mathrm{p}$ & Significant effect/path \\
\hline \multicolumn{6}{|c|}{ IV to Mediators (a path) } \\
\hline $\mathrm{OC} \rightarrow \mathrm{OL}$ & 0.484 & 0.074 & 6.50 & 0.000 & Exist \\
\hline \multicolumn{6}{|c|}{ Direct Effects of Mediators on DV (b path) } \\
\hline $\mathrm{OL} \rightarrow \mathrm{OI}$ & .313 & .0425 & 7.311 & 0.000 & Exist \\
\hline \multicolumn{6}{|c|}{ Total Effect of IV on DV (c path) } \\
\hline $\mathrm{OC} \rightarrow \mathrm{OI}$ & 0.451 & 0.057 & 7.84 & 0.000 & Exist \\
\hline \multicolumn{6}{|c|}{ Direct Effect of IV on DV (c' path) } \\
\hline $\mathrm{OC} \rightarrow \mathrm{OI}$ & 0.299 & 0.056 & $5.290 \mathrm{~s}$ & 0.000 & Exist \\
\hline
\end{tabular}

Model Summary for DV Model:

$\mathrm{F}(2,276)=64.027, \alpha=0.000<\mathrm{p}=0.01$

R-Square: 0.3169

Adjusted R-Square: 0.3120

Table 6. Normal theory tests for indirect effects $(\mathrm{N}=279)$

\begin{tabular}{llllll}
\hline Indirect effect & Effect & $(\mathrm{SE})$ & $\mathrm{Z}$ & $\mathrm{p}$ & Mediation \\
\hline $\mathrm{OC} \rightarrow \mathrm{OL} \rightarrow \mathrm{OI}$ & 0.1521 & 0.0301 & 4.895 & 0.000 & Exist \\
\hline
\end{tabular}

Table 7. Bootstrapping results for indirect effects-mediation analysis $(\mathrm{N}=279)$

\begin{tabular}{llllllll}
\hline Indirect effect & $\begin{array}{l}\text { Beta } \\
\text { Boot }\end{array}$ & $\mathrm{SE}$ & $\begin{array}{l}\mathrm{I} / \mathrm{D} \\
\mathrm{ab} / \mathrm{c}^{\prime}\end{array}$ & $\begin{array}{l}\mathrm{I} / \mathrm{D}+\mathrm{I} \\
\mathrm{ab} / \mathrm{c}\end{array}$ & $\begin{array}{l}\text { Bootstrapping } \\
\text { Confidence Intervals }\end{array}$ & $\begin{array}{l}\text { M5\% } \\
\text { exist }\end{array}$ \\
\hline $\mathrm{OC} \rightarrow \mathrm{OL} \rightarrow \mathrm{OI}$ & 0.1521 & 0.034 & $50.8 \%$ & $33.7 \%$ & 0.091 & 0.228 & Yes \\
\hline
\end{tabular}

Note. The variance accounted for (VAF) determines the size of the indirect effect in relation to the total effect $(\mathrm{D}+\mathrm{I}): \mathrm{VAF}>80 \%=$ Large Effect and full Mediation, $80 \%>\mathrm{VAF}>20 \%=$ Partial Mediation, $\mathrm{VAF}<20 \%=$ almost there is no mediation. 
See Hayes, A. F. (2009). Beyond Baron and Kenny: Statistical mediation analysis in the new millennium. Communication Monographs, 76, 408-420, Or Hayes, A. F. (2013). Introduction to mediation, moderation, and conditional process analysis: A regression-based approach. New York: The Guilford Press

Table 8. Summary of mediation hypotheses

\begin{tabular}{llll}
\hline $\mathrm{N}$ & Relationship & Hypothesis statement & Decision \\
\hline $\mathrm{H} 4$ & OC $\rightarrow$ OL $\rightarrow$ OI & OL mediates the relationship between OC on OI. & Supported \\
\hline
\end{tabular}

\section{Discussion}

Four hypotheses were proposed/hypothesized to test for the direct effect of antecedents on consequent variables/constructs. In terms of the antecedents of OI (the phenomenon of interest of current study), OL demonstrated the highest coefficients $($ Beta $=0.397)$. In other words, in a linear combination of OC and OL to predict the variations in OI, OL contributes the most to the variation in OI with a medium to large effect size. OC is a significant predictor of OL. Therefore, much attention needs to be paid on enhancing OC. In other words, although innovation is determined/depend on learning (OL) in an organization, an improvement in culture (OC) can considerably/saliently improve innovation (OI) as well as learning (OL). From a practical point of view this means that if a manager is interested to increase the innovation (perception of innovation) in an organization, he/she would better to pay a substantial attention to learning (OL) in given organization. Besides, the effect/impact of organization culture on variation of organization innovation is substantial. Therefore, a policy that seeks to improve the $\mathrm{OI}$ needs to introduce a combination of $\mathrm{OL}$ and culture practices.

Further, the partial regression coefficients in the model have different interpretations. For OC, two organizations which are equal in OL but differ one unit in their OC practices are estimated to differ by 0.284 units in practicing of innovation in their organization. And eventually, in terms of the positive effect of OC on OL, two organizations differ one unit in their OC practices are estimated to differ by 0.367 units in OL in their organization.

Another part of findings of structural model concerns the $\mathrm{R}$ squares as the capability of the overall model to predict the phenomenon of interest. The $\mathrm{R}$ squares calculated for OI equals to $\mathrm{R}^{2}=0.321$ or $32.1 \%$ which according to Cohen's table of population effect size and given formula, $\mathrm{f}^{2}=\mathrm{R}^{2} /\left(1-\mathrm{R}^{2}\right)$, is large. Effect size (ES) is the degree to which $\mathrm{H}_{0}$ is false is indexed by the discrepancy between $\mathrm{H}_{0}$ and $\mathrm{H}_{1}$. In other words, a large ES increase the confidence that the significant finding is not spurious. The large effect size of $\mathrm{R}$ squares supported the significant tests and proved that a linear combination of all variables in the model is significantly and sufficiently predicting the phenomenon of interest (OI). In other words, the result of measurement model proved that the model is valid and reliable while the results of structural model proved that the model is authentic. However, another $67.9 \%(100-32.1)$ of variation in OI has been remained unexplained in this model and therefore, further study is needed to find the other necessary variables.

\section{Conclusion}

This study inspects the associations between OC, OI and OL. The result of this study discloses that OC exerts a comprehensive mediating impact over OI by means of organization learning. Conversely, members in organizations with vast experience and OC may improve the organizational performance. On the basis of this study, it is comprehensible that OC plays an important part in innovation. It is considerable for professionals of both OC and innovation to comprehend the systemic correlation among these conceptions and the significance that it is able to generate given that producing and sustaining competitive advantage in favour of organizations.

\section{References}

Alvesson, M. (2012). Understanding organizational culture. Sage.

Amabile, T. M., Conti, R., Coon, H., Lazenby, J., \& Herron, M. (1996). Assessing the work environment for creativity. Academy of Management Journal, 39(5), 1154-1184. http://dx.doi.org/10.2307/256995

Argote, L. (2013). Organizational learning: Creating, retaining and transferring knowledge. Springer. http://dx.doi.org/10.1007/978-1-4614-5251-5

Azadi, A., Farsani, M. E., Rizi, R. M., \& Aroufzad, S. (2013). Relationship between organizational culture and organizational learning among employees in physical education organizations. European Journal of Sports and Exercise Science, 2(1), 12-16. 
Barclay, D., Higgins, C., \& Thompson, R. (1995). The partial least squares (PLS) approach to causal modeling: Personal computer adoption and use as an illustration. Technology Studies, 2(2), 285-309.

Baron, R. M., \& Kenny, D. A. (1986). The moderator-mediator variable distinction in social psychological research: conceptual, strategic, and statistical considerations. Journal of Personality and Social Psychology, 51, 1173-1182. http://dx.doi.org/10.1037/0022-3514.51.6.1173

Bollen, K. A. (1989). Structural Equations with Latent Variables.

Bryman, A., \& Bell, E. (2007). Business research methods. Oxford University Press, USA.

Cameron, K. S., \& Quinn, R. E. (2006). Diagnosing and Changing Organizational Culture, 2. San Francisco: Aufl.

Cameron, K., \& Quinn, S. (1999). Diagnosing and changing organizational culture.

Cheng, C. J., \& Shiu, E. C. (2008). Re-innovation: The construct, measurement, and validation. Technovation, 28(10), 658-666. http://dx.doi.org/10.1016/j.technovation.2007.08.002

Chin, W. W. (1998a). In G. A. Marcoulides (Ed.), The partial least squares approach for structural equation modeling. Lawrence Erlbaum Associates.

Chin, W. W. (1998b). The partial least squares approach to structural equation modeling. Modern Methods for Business Research, 295-336.

Chin, W. W. (2010). In V. E. Vinzi et al. (Eds.), How to Write Up and Report PLS Analyses Handbook of Partial Least Squares. Berlin Heidelberg: Springer-Verlag.

Cooke, P. (2001). Regional innovation systems, clusters, and the knowledge economy. Industrial and corporate change, 10(4), 945-974. http://dx.doi.org/10.1093/icc/10.4.945

Czerniewicz, L., \& Brown, C. (2009). A study of the relationship between institutional policy, organisational culture and e-learning use in four South African universities. Computers \& Education, 53(1), 121-131. http://dx.doi.org/10.1016/j.compedu.2009.01.006

Damanpour, F., Walker, R. M., \& Avellaneda, C. N. (2009). Combinative effects of innovation types and organizational performance: A longitudinal study of service organizations. Journal of Management Studies, 46(4), 650-675. http://dx.doi.org/10.1111/j.1467-6486.2008.00814.x

Easterby-Smith, M., \& Lyles, M. A. (2011). Handbook of organizational learning and knowledge management: Wiley.

Fornell, C., \& Cha, J. (1994). Partial least squares. Cambridge, MA: Blackwell.

Fornell, C., \& Larcker, D. F. (1981). Evaluating structural equation models with unobservable variables and measurement error. Journal of Marketing Research, 18(1), 39-50. http://dx.doi.org/10.2307/3151312

Gil-Garcia, J. R. (2008). Using partial least squares in digital government research. Handbook of research on public information technology, 239-253. http://dx.doi.org/10.4018/978-1-59904-857-4.ch023

Hair, J. F., Hult, G., Ringle, C. M., \& Marko Sastedt. (2013). A Primer on Partial Least Squares Structural Equation Modeling (PLS-SEM) (1st ed.). SAGE.

Hair, J. F., Ringle, C. M., \& Sarstedt, M. (2011). PLS-SEM: Indeed a Silver Bullet. Journal of Marketing Theory and Practice, 18(2), 139-152. http://dx.doi.org/10.2753/MTP1069-6679190202

Hair, J. F., Ringle, C. M., \& Sarstedt, M. (2012). Partial least squares: the better approach to structural equation modeling? Long Range Planning, 45(5), 312-319. http://dx.doi.org/10.1016/j.lrp.2012.09.011

Hair, J. F., Ringle, C. M., \& Sarstedt, M. (2013). Partial least squares structural equation modeling: rigorous applications, better results and higher acceptance. Long Range Planning, 46(1-2), 1-12. http://dx.doi.org/10. 1016/j.lrp.2013.01.001

Hair, J. F., Sarstedt, M., Pieper, T. M., \& Ringle, C. M. (2012). Applications Of Partial Least Squares Path Modeling In Management Journals: A Review Of Past Practices And Recommendations For Future Applications. Long Range Planning, 45(5-6), 320-340. http://dx.doi.org/10.1016/j.lrp.2012.09.008

Hair, J. F., Sarstedt, M., Ringle, C. M., \& Mena, J. A. (2012). An Assessment of the Use of Partial Least Squares Structural Equation Modeling in Marketing Research. Journal of the Academy of Marketing Science. http://dx.doi.org/10.1007/s11747-011-0261-6

Harman, H. H. (1976). Modern Factor Analysis. 
Hayes, A. F. (2013). Introduction to mediation, moderation, and conditional process analysis. A regression-based approach: Guilford Press.

Henseler, J., Ringle, C. M., \& Sarstedt, M. (2012). Using partial least squares path modeling in international advertising research: Basic concepts and recent issues. In S. Okazaki (Ed.), Handbook of Research in International Advertising (pp. 252-276). Cheltenham: Edward Elgar Publishing. http://dx.doi.org/10.4337/ 9781781001042.00023

Henseler, J., Ringle, C. M., \& Sinkovics, R. R. (2009). The Use of Partial Least Squares Path Modeling in International Marketing. In R. R. Sinkovics, \& P. N. Ghauri (Eds.), Advances in International Marketing (Vol. 20, pp. 277-320). Bingley: Emerald. http://dx.doi.org/10.1108/S1474-7979(2009)0000020014

Hurmelinna-Laukkanen, P., Sainio, L. M., \& Jauhiainen, T. (2008). Appropriability regime for radical and incremental innovations. $R \& d$ Management, 38(3), 278-289.

Imran, M., Hasan, S., Rizvi, M., \& Ali, B. (2011). Impact of Organizational Learning on Organizational Performance. International Journal of Academic Research, 3(4), 424-427.

Klarner, P., Sarstedt, M., Hoeck, M., \& Ringle, C. M. (2013). Disentangling the effects of team competences, team adaptability, and client communication on the performance of management consulting teams. Long Range Planning. http://dx.doi.org/10.1016/j.1rp.2013.03.001

Leal-Rodríguez, A., Leal-Millán, A., Roldán-Salgueiro, J. L., \& Ortega-Gutiérrez, J. (2013). Knowledge Management and the Effectiveness of Innovation Outcomes: The Role of Cultural Barriers. Electronic Journal of Knowledge Management, 11(1).

Liao, S. H., \& Wu, C. C. (2010). System perspective of knowledge management, organizational learning, and organizational innovation. Expert Systems with Applications, 37(2), 1096-1103. http://dx.doi.org/10.1016/j. eswa.2009.06.109

Macher, J. T. (2014). Managing Complexity at the Boundaries of the Firm: A Knowledge-Based Examination in Medical Device Manufacturing.

Marins, L. M. (2008). The challenge of measuring innovation in emerging economies' firms: A proposal of a new set of indicators on innovation. United Nations University, Maastricht Economic and social Research and training centre on Innovation and Technology.

McEvily, S. K., \& Chakravarthy, B. (2002). The persistence of knowledge-based advantage: An empirical test for product performance and technological knowledge. Strategic Management Journal, 23(4), 285-305. http://dx.doi.org/10.1002/smj.223

Podsakoff, P. M., \& Organ, D. W. (1986). Self-reports in organizational research: Problems and prospects. Journal of Management, 12(4), 531-544. http://dx.doi.org/10.1177/014920638601200408

Quinn, R. E., \& Rohrbaugh, J. (1983). A spatial model of effectiveness criteria: towards a competing values approach to organizational analysis. Management Science, 29(3), 363-377. http://dx.doi.org/10.1287/ mnsc.29.3.363

Ringle, C. M., Wende, S., \& Will, A. (2005). Smart PLS Version 2.0 M3.

Sanz-Valle, R., Naranjo-Valencia, J. C., Jiménez-Jiménez, D., \& Perez-Caballero, L. (2011). Linking organizational learning with technical innovation and organizational culture. Journal of knowledge management, 15(6), 997-1015. http://dx.doi.org/10.1108/13673271111179334

Senge, P. M. (1994). The fifth discipline field book. Random House Digital, Inc.

Smith, K. G., Collins, C. J., \& Clark, K. D. (2005). Existing knowledge, knowledge creation capability, and the rate of new product introduction in high-technology firms. Academy Of Management Journal, 48(2), 346-357. http://dx.doi.org/10.5465/AMJ.2005.16928421

Sobel, M. E. (1982). Asymptotic Confidence Intervals for Indirect Effects in Structural Equation Models. Sociological Methodology, 13, 290-312. http://dx.doi.org/10.2307/270723

Tobin, D. R. (1993). Re-educating the corporation: Foundations for the learning organization. Omneo Essex Junction, VT.

Vasenska, I. (2013). Organizational Learning and Employee Empowering Increasing Tourist Destination Performance. Proceedings of the 2013 Active Citizenship by Knowledge Management \& Innovation: Proceedings of the Management, Knowledge and Learning International Conference 2013, 615-624. 
Weerawardena, J., O'Cass, A., \& Julian, C. (2006). Does industry matter? Examining the role of industry structure and organizational learning in innovation and brand performance. Journal of Business Research, 59(1), 37-45. http://dx.doi.org/10.1016/j.jbusres.2005.02.004

\section{Copyrights}

Copyright for this article is retained by the author(s), with first publication rights granted to the journal.

This is an open-access article distributed under the terms and conditions of the Creative Commons Attribution license (http://creativecommons.org/licenses/by/3.0/). 